\title{
Research Paper Explaining status and scope of pomegranate production in India: An economic analysis
}

\section{- Prem Narayan and Subhash Chand}

See end of the paper for authors' affiliations

Correspondence to :

Prem Narayan

ICAR-National Institute of Agricultural Economics and Policy Research, Pusa

(New Delhi) India

Email: prem.narayan@icar. gov.in
Paper History :

Received : 14.12.2019;

Revised : 09.07.2020;

Accepted : 11.08 .2020
ABSTRACT : The pomegranate was found very profitable crop as compared to others traditional food and oilseeds crops. Laying the route map to double the farmer's income has decided to double farmers' income by 2022 by improving technology and policy, increasing milk production and high value crops production like; fruits and vegetable. It will require annual growth rate 10.4 per cent (Ramesh Chand, 2017). The area and production of the pomegranate was recorded 124 thousand hectares, 884 thousand tons and productivity 71.3 quintals, respectively during 2007-08. There was seen quantum jump in both area and production from 113 to 216 thousand hectares about twice and 745 to 2613 thousand tons almost 3.5 times, respectively, during 2012-13 to 2016-17. The highest share of major importing countries like; United Arab Emirates 42.82 per cent, Bangladesh 24.49 per cent, Nepal 8.03 per cent, Saudi Arabia 5.87, Kuwait 2.57 per cent, Netherland 2.53 and the other like Sri Lanka, Thailand, Bahrain and Malaysia below 2 per cent during (TE) 2016-17. A basket of the pomegranate has embedded in human history and its utilization was associated with several ancient cultures for its fruit, nutritional and medicinal value of pharmaceutical industries. In the recent past, its wide range of significance in human health, malnutrition and provide better livelihood security in rural and urban areas. Therefore, production of pomegranate not only will boost the income of the farmers but also ensure the social security in India.

KEY WORDS : Pomegranate, Growth rate, Doubling income, Import, Export

How To Cite This PAper : Narayan, Prem and Chand, Subhash (2020). Explaining status and scope of pomegranate production in India: An economic analysis . Internat. Res. J. Agric. Eco. \& Stat., 11 (2) : 157-165, DOI : 10.15740/ HAS/IRJAES/11.2/157-165. Copyright@2020:Hind Agri-Horticultural Society. 